\title{
Myocarditis heart failure: A review of clinical status and meta-analyses of diagnostic performance of cardiac magnetic resonance and therapeutic value of immunosuppressive therapy
}

\author{
Aref Albakri* \\ St-Marien hospital Bonn Venusberg, department of internal medicine, Bonn, Germany
}

\begin{abstract}
Myocarditis heart failure or inflammatory cardiomyopathy is a polymorphic disease complicated by heterogeneous clinical presentation and evolution. Patients with myocarditis presenting with severe left ventricular (LV) dysfunction and life-threatening arrhythmias represent a demanding challenge to clinicians. Although molecular evaluation of the myocardium using endomyocardial biopsy and modern techniques of cardiovascular imaging provide valuable insights into its etiology and pathophysiology, diagnosis remains a clinical challenge because of varied modes of clinical presentation, diversity of approaches to diagnosis, a spectrum of clinical courses and unsettled perspective on therapeutics in different patient settings and viral pathologies. This review seeks to frame recent clinical advances in diagnosing and managing myocarditis HF within the latest understanding of clinical presentation, etiology and pathophysiology obtained from experimental animal models and clinical trials. The objective is to improve understanding of the clinical status of myocarditis heart failure.
\end{abstract}

\section{Introduction}

Heart failure (HF) is the culmination of many forms of heart diseases. It manifests as signs and symptoms suggesting cardiac dysfunction. Objective evidence of cardiac dysfunction is necessary for diagnosis [1], and the identification of the underlying etiology is key to guide diagnostic, therapeutic and prophylactic strategies [2]. However, the current HF classification systems: anterograde vs. retrograde, acute vs. chronic, left vs. right, and systolic vs. diastolic do not focus on the underlying etiology rather on cardiac dysfunction or time of onset [2]. These classification systems motivate research on objective assessment of cardiac structure and function as the basis for diagnosis and treatment. In fact, the leading heart and cardiology societies such as American Heart Association (AHA) [3] and European Society of Cardiology (ESC) Working Group on Myocardial and Pericardial Diseases [4] refer to myocarditis as one of the causes of dilated cardiomyopathy (DCM) or a form of inflammatory cardiomyopathy. The consequence is research on myocarditis as a distinct form of HF has lagged far behind that of other common forms of HF. Thus, the present paper reviews published evidence including two meta-analyses of diagnostic performance of cardiac magnetic resonance imaging and therapeutic value of immunosuppression or immunomodulation on patients with myocarditis HF.

\section{Brief history}

The seminal description of an inflammatory disease of the heart and the difficulty in its detection appeared in the publication "Treatise on Disease of the Heart" in 1749 by a French physician, Jean Baptiste Senac. Later in 1873, Joseph Freidrich Sobernheim originated the term myocarditis. Initially, the term included other undocumented forms of cardiomyopathies and HF such as ischemic heart disease and hypertensive heart disease [6]. In 1980, the World Health Organization (WHO) and the International Society and Federation of Cardiology (ISFC) made the initial attempt to differentiate between myocarditis, and other forms of cardiomyopathies and HF [7]. Since then, endomyocardial biopsies of DCM patients and studies exploring the natural history of patients with selected conditions such as Chagas disease have established that myocarditis is majorly a viral infection causing immunologic damage to the myocardium culminating in DCM with LV dysfunction [3]. The term has now been refined to apply to acute or chronic inflammation of the heart muscles to environmental or endogenous triggers most commonly viruses and less frequently bacterial, fungi and parasites, and non-infectious causes such as systemic autoimmune responses and drug-induced hypersensitivity [8]. Myocarditis HF has also been referred to as inflammatory cardiomyopathy mainly because myocarditis mainly progresses into HF through DCM. The lack of a uniform terminology complicates comparison of studies across countries or healthcare systems to develop a universal understanding of myocarditis HF.

\section{Definition}

Myocarditis is an inflammatory disease of the myocardium frequently caused by a viral infection and/or post-viral immune-

${ }^{\star}$ Correspondence to: Aref Albakri, St-Marien hospital Bonn Venusberg, department of internal medicine, Bonn, Germany, E-mail: arefalbakri@yahoo.com

Key words: myocarditis heart failure, inflammatory cardiomyopathy, inflammatory dilated cardiomyopathy

Received: October 22, 2018; Accepted: October 31, 2018; Published: November 09,2018 
Albakri A (2018) Myocarditis heart failure: A review of clinical status and meta-analyses of diagnostic performance of cardiac magnetic resonance and therapeutic value of immunosuppressive therapy

mediated responses [9]. The ESC describes it as an acute inflammatory disorder of the heart muscle often with preserved left ventricular (LV) function [4]. It manifests with a spectrum of symptoms ranging from mild dyspnea to cardiogenic shock and sudden death. Its longterm consequence is DCM with chronic HF [10]. The AHA refers to myocardial HF as inflammatory cardiomyopathy resulting from acute or chronic inflammatory processes affecting the myocardium produced by a variety of toxins and drugs such as cocaine and interleukin 2 or by infection agents mostly viral and/or bacterial, rickettsial, fungal or parasitic [3]. The ESC goes further to describe myocarditis HF by the presence of chronic inflammatory cells (cellular infiltrate and myocyte necrosis) accompanied by LV dilatation and depressed ejection fraction detected by histology and/or immunocytochemistry analyses [4]. Beside toxins and drugs, myocarditis HF may result from autoimmune and systemic diseases such as Whipple disease, giant cell myocarditis (GCM) and hypersensitive reaction to drugs such as antibiotics, sulfonamides, anticonvulsants and anti-inflammatories [3].

\section{Epidemiology}

Accurate population-based estimates of the incidence and prevalence of myocarditis HF has been difficult to determine mainly because of widely varying clinical presentation and reduced utility of endomyocardial biopsy due to perceived risks, and the lack of widely accepted and sensitive histologic standards [10]. The wide diversity of clinical manifestations from non-specific symptoms to severe myocardial destruction potentially underestimates the current epidemiological estimates of myocarditis HF [6]. The 2013 global burden of myocarditis report based on hospital dismissal data found the burden of myocarditis as a percentage of HF varies by age and region from $0.5 \%$ to $4.0 \%$ [5]. In a systematic analysis for the Global Burden of Disease Study 2013, the estimated global prevalence of myocarditis HF was 22 of 100,000 patients annually [12]. A recent scientific statement by the AHA and the American College of Cardiology (ACC) on eligibility and disqualification recommendations for competitive athletes with cardiovascular abnormalities rank myocarditis as the third leading cause of sudden cardiac death (SCD) in competitive athletes [13]. In a study of suspected myocarditis on 672,672 male military recruits (mean age 20 years), 98 had myocarditis mimicking myocardial infarction, one case of SCD and nine cases of DCM in the initial stages of clinical disease [14]. Autopsy studies report an incidence of myocarditis according to population studied ranges between $0.11 \%$ and $12 \%$ [15-19].

The prevalence of myocarditis HF is higher in men [20-22]. According to mouse model of myocarditis, sex hormones may mediate the differences in gender prevalence of myocarditis HF [23,24]. In female mice, estrogenic hormones protect against viremia (presence of virus in blood) and viral infectivity of cardiomyocytes while decreasing harmful myocardial inflammatory reaction [23]. Conversely, in male mice, testosterone has a detrimental effect via the inhibition of antiinflammatory response [24]. Current evidence also suggests a higher prevalence in young adults. The mean age of patients with GCM is 42 years [25] and the mean age of adult patients with other forms of myocarditis ranges from 20 to 51 years [26,27]. The consequences in this population are severe. Autopsy reports show myocarditis causes SCD in up to $12 \%$ in patients aged $<40$ years $[19,27,28]$ and in military recruits [14] and young athletes [13]. Myocarditis has also been associated with higher rates of SCD and cardiomyopathy in pediatric populations [29$31]$, with the risk of death and heart transplantation persisting up to 12 years [32]. The presence of co-morbidities such as cardiac amyloidosis, hypertrophic cardiomyopathy or arrhythmogenic right ventricular dysplasia have been associated with poor prognosis [33-35].

\section{Etiology}

The position statement from the 2013 ESC Working Group on myocardial and pericardial diseases lists large variety infectious agents, systemic diseases, drugs and toxins as common causes of myocarditis HF (Table 1).

\section{Viral etiologies}

The predominant cause of myocarditis are infectious agents with viral etiologies largely prevailing over other causes as well as represents the most studied etiology of myocarditis HF [36]. In Europe and the United States, Coxsackie virus, parvovirus B19, HHV-6 type B and the adenovirus are the most frequently encountered viral etiologies in

Table 1. Common causes of myocarditis heart failure

\begin{tabular}{|c|c|c|}
\hline Category & Causes & Examples \\
\hline \multirow{6}{*}{ Infectious Agents } & Viral & $\begin{array}{l}\text { RNA viruses: Coxsackieviruses A/B, echoviruses, polioviruses, HIV, influenza A-B/mumps/measles/rubella/hepatitis/dengue/ } \\
\text { yellow fever/Chikungunya/Junin/Lassa fever/rabies virus } \\
\text { DNA viruses: adenoviruses, parvovirus B19, cytomegalovirus, HHV-6, Epstein-Barr/varicella-zoster/herpes simplex/variola/ } \\
\text { vaccinia virus }\end{array}$ \\
\hline & Bacterial & $\begin{array}{l}\text { Staphylococcus, Streptococcus, Pneumococcus, Meningococcus, Gonococcus, Salmonella, Corynebacterium diphtheriae, } \\
\text { Haemophilus influenzae, Mycobacterium, Mycoplasma pneumoniae, Brucella }\end{array}$ \\
\hline & Fungal & Aspergillus, Actinomyces, Blastomyces, Candida, Coccidioides, Cryptococcus, Histoplasma, Mucormycoses, Nocardia, Sporothrix \\
\hline & Protozoal & Trypanosoma cruzi, Toxoplasma gondii, Entamoeba, Leishmania \\
\hline & Parasitic & Trichinella spiralis, Echinococcus granulosus, Taenia solium \\
\hline & Rickettsial & Coxiella burnetii, R. rickettsii, R. tsutsugamuschi \\
\hline \multirow{3}{*}{$\begin{array}{l}\text { Immune-mediated } \\
\text { Responses }\end{array}$} & Allergens & $\begin{array}{l}\text { Tetanus toxoid, vaccines, serum sickness, drugs (penicillin, cefaclor, colchicine, furosemide, isoniazid, lidocaine, tetracycline, } \\
\text { sulfonamides, phenytoin, phenylbutazone, methyldopa, thiazide diuretics, amitriptyline) }\end{array}$ \\
\hline & Alloantigens & Heart transplant rejection \\
\hline & Autoantigens & $\begin{array}{l}\text { Infection-negative lymphocytic, infection-negative giant cell and immune-oriented disorders (systemic lupus erythematosus, } \\
\text { rheumatoid arthritis, Churg-Strauss syndrome, Kawasaki's disease, inflammatory bowel disease, scleroderma, polymyositis, } \\
\text { myasthenia gravis, insulin-dependent diabetes mellitus, thyrotoxicosis, sarcoidosis, Wegener's granulomatosis, rheumatic heart } \\
\text { disease. }\end{array}$ \\
\hline \multirow{4}{*}{ Drugs \& Toxins } & Drugs & $\begin{array}{l}\text { Amphetamines, anthracyclines, cocaine, cyclophosphamide, ethanol, fluorouracil, lithium, catecholamines, hemetine, interleukin-2, } \\
\text { trastuzumab, clozapin }\end{array}$ \\
\hline & Heavy metals & Copper, iron, lead (rare, more commonly cause intramyocyte accumulation) \\
\hline & Physical Agents & Radiation, electric shock \\
\hline & Hormones & Phaeochromocytoma, vitamins: beriberi \\
\hline
\end{tabular}

HHV: Human Herpes Virus; HIV: Human Immunodeficiency Virus. Adapted from the ESC Working Group on Myocardial and Pericardial Diseases, p.2638 [11] 
Albakri A (2018) Myocarditis heart failure: A review of clinical status and meta-analyses of diagnostic performance of cardiac magnetic resonance and therapeutic value of immunosuppressive therapy

acute myocarditis in children and young adults $(<35$ years $)$ [37-39]. In the past two decades, polymerase chain reaction (PCR) and in situ hybridization in heart biopsy samples have been able to identify a range of other cardiotropic viruses involved in the pathology of myocarditis including H1N1 strains of influenza [40], adenovirus [38,41], Hepatitis C [42,43], human immunodeficiency virus (HIV) [4] and cytomegalovirus, echovirus, parvovirus B-19, and Epstein-Barr virus [45]. In the case of chronic myocarditis, there is absence of data from transverse or longitudinal studies to determine the incidence of various viral etiologies of cardiac infection. However, viral persistence was associated with ventricular dysfunction while viral genome clearance was associated with hemodynamic improvement [37].

\section{Non-viral etiologies}

In select populations, specific non-viral infections and autoimmune syndromes have also been implicated as important etiologies of myocarditis [8]. Autoimmune reaction following untreated streptococcal infection may lead to rheumatic carditis [46]. Bacterial infection (diphtheria and borrelia burgdorferi) or parasites (Chagas disease) are important non-viral etiologies in specific regions $[47,48]$. Hypersensitivity myocarditis may be a consequence of exposure of various drugs, toxins or vaccine-specific cardiac autoimmune responses [8]. Most cases of hypersensitivity myocarditis develop early in the course of drug use but an estimated $15 \%$ of clozapine-induced myocarditis may develop later, up to two years following the initiation of drug therapy $[49,50]$. Vaccination against smallpox infection has also been linked to myopericarditis in up to 6 in 10,000 vaccines [51]. Other non-viral and non-infectious etiologies of myocarditis include cardiac inflammation following exposure to radiation, systemic autoimmune diseases such as antinuclear antibody-related vasculitis, systemic sclerosis, lupus erythematosus, and celiac disease [52].

\section{Pathophysiology}

Although the precise pathophysiologic mechanisms of myocarditis in humans is not well established, accumulating evidence suggests it is the result of viral and autoimmune mechanisms acting in the presence of a genetic predisposition (familial) or occurring sporadically [5357]. However, the bulk of the evidence on the pathophysiology of myocarditis relies on murine models of enterovirus myocarditis. The evidence suggests myocarditis develops in three phases: acute phase, sub-acute phase and chronic phase [58-62] (Figure 1).

\section{Phase 1: Acute phase}

The initial (or acute) phase begins with enteroviruses preferentially entering cardiomyocytes through specific receptors leading to severe cytopathic effect due to virus replication about two weeks post-infection. Consequently, humoral and cellular immune reaction comprising of macrophages, and CD4+ and CD8+ T- lymphocytes are initiated leading to the elimination of the infectious agent within two weeks post-infection in resistant mice strains. In susceptible mice strains, viral RNA and inflammation persists for several weeks [61-62]. The ongoing infection and inflammation triggers autoimmune responses in the heart resulting from cardiomyocyte necrosis and subsequent release of self-antigens previously hidden to the immune system. The susceptible mice strains may develop autoimmune lymphocytic or GCM and later DCM after immunization with cardiac auto-antigens or spontaneously [64]. After viral entry acute injury of the cardiomyocytes induced by virus replication results in cardiomyocyte necrosis, the exposure of intracellular antigens and the activation of host autoimmune response. Autoimmune response increases cardiac cell injury and can result in efficient viral clearance, corresponding clinically to subclinical myocarditis [36]. The acute phase occurs in a few days [9]. In clinical practice, this phase is often asymptomatic [63].

\section{Phase II: Subacute phase}

The second (or sub-acute) phase, which covers a few weeks to several months, is characterized by autoimmune reaction. Activated virus specific T-lymphocytes may attack the host's organs by molecular mimicry (some host myocardial cellular antigens sharing epitopic similarities with viral antigens). Cytokine activation (tumor necrosis factor [TNF]-alpha and interleukin (IL)-1 and -6) and antibodies to viral and cardiac proteins may aggravate cardiac damage leading to contractile dysfunction [9,36]. In most patients with myocarditis, immune response decreases with virus elimination and LV function recovers but in some murine models autoimmune responses persists independent of virus genome in the myocardium and could progress into the chronic phase [59].

\section{Phase III: Chronic phase}

In the third (or chronic) phase, pathological manifestations of myocarditis disappear and the destroyed cardiomyocytes are replaced by diffuse fibrosis [65]. Autoantibodies to several cardiac antigens are common in patients with myocarditis and DCM and suspected to

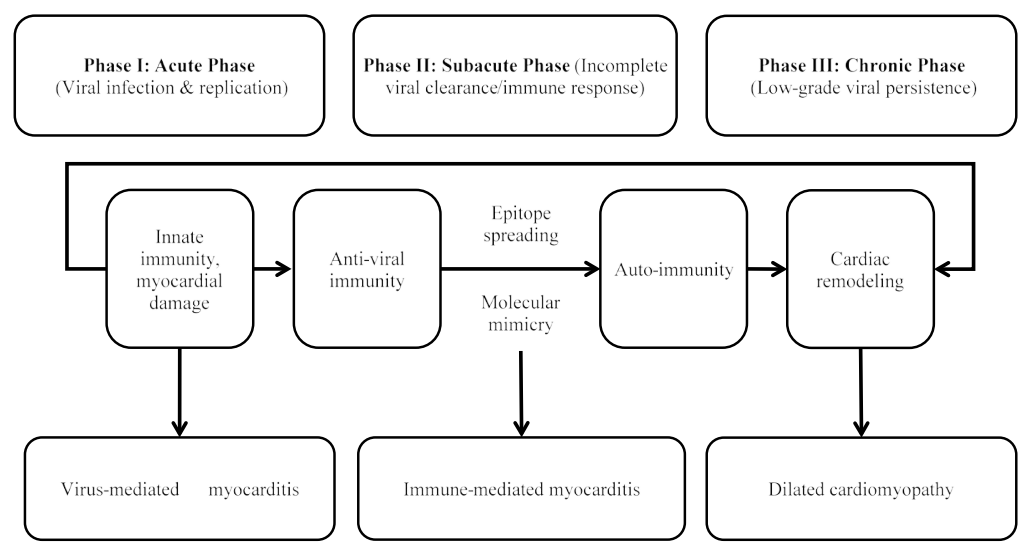

Figure 1: Pathophysiology of myocarditis heart failure

Pathophysiology of myocarditis is triphasic. Phase I: Viral infection and replication in the heart inducing innate immune responses. Phase II: Myocardial damage induces autoantibodies and autoimmune T-cells responses via epitope spreading or molecular mimicry. Phase III: Low-grade viral persistence and inflammation causes remodeling contributing to dilated cardiomyopathy. Adapted from Martinez et al., 2012 [63] 
Albakri A (2018) Myocarditis heart failure: A review of clinical status and meta-analyses of diagnostic performance of cardiac magnetic resonance and therapeutic value of immunosuppressive therapy

precede the development of myocarditis HF. Antibodies acting against beta- 1 adrenergic receptors have been found in serum of myocarditis and DCM patients and their removal by immuno-absorption improved cardiac function [10]. In some hosts, molecular mimicry induces an autoimmune trait sustaining the inflammatory reaction to cause chronic inflammation or DCM. This phase is characterized by biventricular dilatation with $\mathrm{HF}$ associated with persistent virus or latent endomyocardial replication, dilatation, and contractile dysfunction [66].

\section{Clinical presentation}

The 2013 ESC guidelines on myocardial and pericardial diseases proposed criteria for raising clinical suspicion of myocarditis HF based on the clinical course of the disease alongside common clinical signs and symptoms of biopsy-proven human myocarditis (Table 2).

Myocarditis varies with a broad spectrum of symptoms ranging from asymptomatic courses to manifestations with signs of myocardial infarction to life threatening cardiogenic shock and ventricular arrhythmias [11]. However, its three common clinical presentation are chest pain mimicking MI, ventricular arrhythmias and HF due to a new onset of DCM. Myocarditis affects individuals of all ages but it is most frequent in young adults. The diversity of clinical presentation in the course of the disease makes diagnosis based on symptoms difficult and thus requires a high level of suspicion early in the course of the disease and the utility of appropriate tests to identify its cause $[9,11]$. When myocarditis is suspected, the ESC recommends the exclusion of CAD and other known cardiovascular diseases such as hypertension and extra cardiac non-inflammatory diseases capable of causing the clinical presentation. It is uncommon for patients with other cardiovascular disorders such as $\mathrm{CAD}$, cardiomyopathy and hypertensive heart disease to present with clinical deterioration caused by myocarditis. If symptoms are unclear or inconclusive, endomyocardial biopsy (EMB) may be considered to confirm myocarditis. Myocarditis could be an incidental finding in autopsy studies of non-cardiac deaths or from myocardial samples obtained for clinical reasons unrelated to myocarditis such as after valve surgery or explanted hearts from patients who received inotropic drugs. In such scenario, the significance of inflammation should be interpreted with caution [11].

\section{Diagnosis}

\section{Diagnostic criteria}

Definitive diagnosis of myocarditis with HF poses significant challenges. No population-based epidemiological study has comprehensively documented the range of clinical manifestations of acute or chronic myocarditis likely because of varied modes of clinical presentation and the lack of reliable non-invasive cardiac imaging tests reduces the yield of conclusive diagnostic or prognostic value [6]. Because of its varied mode of presentation and the lack of specific features, diagnosis of myocarditis requires a high level of clinical suspicion and integrated evaluation of clinical and instrumental investigations including biomarkers and virus serology tests, ECG, and cardiac imaging tests: echocardiography and cardiac magnetic resonance (CMR) to identify suspected cases of myocarditis HF while EMB confirms diagnosis. The 2013 ESC pericardial and myocardial guidelines proposed diagnostic criteria for myocarditis (Table 3 ).

\section{Diagnostic tests}

Biomarkers and virus serology: Biomarkers such as troponins or creatine kinase are non-specific but are useful in raising clinical suspicion of myocarditis [67,68]. In acute myocarditis, serum levels of troponins I and $\mathrm{T}$ are higher compared to creatine kinase myocardial band fraction [69]. Non-specific inflammatory markers such as leukocytes and C-reactive protein may also be elevated in acute myocarditis $[68,69]$ but normal values do not exclude acute myocardial inflammatory process [70]. The ESC recommends testing for troponins and C-reactive proteins in all patients suspected with myocarditis [11]. The used of virus serology in patients suspected with myocarditis remains unproven. Comparing nested PCR in EMB, only $4 \%$ of patients with clinically suspected myocarditis had serological evidence of the same viral infection [70]. The ESC does not recommend the utility of virus serology testing in patients suspected with myocarditis [11]. It has limited diagnostic value since most virus involved in the pathogenesis of myocarditis are highly prevalent in the population and most patients referred for diagnosis from a few week to months after acute phase of viral myocarditis has already resolved [9]. The interpretation of antibodies (cardiac and disease-specific for myocarditis/ DCM) assays is complicated by reactivation or reinfection but may be useful autoimmune biomarkers for identifying at risk relatives and patients

Table 2. Clinical manifestations of biopsy-proven human myocarditis

\begin{tabular}{|l|l|}
\hline Course of Disease & Common Clinical Signs and Symptoms \\
\hline \multirow{3}{*}{ Acute Coronary Syndrome-like } & $\begin{array}{l}\text { Acute chest pain: frequently starting 1-4 weeks post respiratory or gastrointestinal infection; frequently associated with severe and recurrent } \\
\text { symptoms; in the absence of angiographic CAD evidence. }\end{array}$ \\
\hline & ST/T wave changes: ST-segment elevation/depression; T-wave inversion \\
\hline With/without normal global or regional LV/RV dysfunction on cardiac imaging \\
\hline With/without increased TnT/Tnl mimicking acute MI \\
\hline $\begin{array}{l}\text { New onset or worsening HF without } \\
\text { CAD and other known causes }\end{array}$ & New onset/progressive HF (2 weeks- 3 months): dyspnea, peripheral edema, chest discomfort, fatigue \\
\hline $\begin{array}{l}\text { Systolic/diastolic dysfunction with/without increased wall thickness, dilated LV/RV on cardiac imaging } \\
\text { known causes }\end{array}$ & Non-specific ECG signs: BBB, AV-block or ventricular arrhythmias \\
\hline Life-threatening condition without CAD \\
and other known causes & Fatigue, palpitations, dyspnea, atypical chest pains, arrhythmias \\
\hline & Systolic/diastolic dysfunction on cardiac imaging suggesting DCM or non-ischemic cardiomyopathy \\
\hline Non-specific ECG signs: BBB, AV-block or ventricular arrhythmias \\
\hline
\end{tabular}

BBB: Bundle branch block; CAD: Coronary Artery Disease; DCM: Dilated Cardiomyopathy; ECG: Electrocardiogram; HF: Heart Failure; LV: Left Ventricle; MI: Myocardial Infarction; RV: Right Ventricle; SCD: Sudden Cardiac Death. A clinically suspected case of myocarditis should meet the following criteria: $\geq 1$ clinical presentation and $\geq 1$ diagnostic criteria in the absence of (a) angiographically detected CAD (coronary stenosis $\geq 50 \%$ ); (b) known pre-existing cardiovascular disease or extra-cardia causes that could explain clinical presentation (valvular heart disease, congenital heart disease, hyperthyroidism). Suspicion increases with higher number of fulfilled criteria. If the patient is asymptomatic, $\geq 2$ criteria should be fulfilled. Adapted from European Society of Cardiology Working Group on Myocardial and Pericardial Diseases, 2013, p. 2642 [11] 
Albakri A (2018) Myocarditis heart failure: A review of clinical status and meta-analyses of diagnostic performance of cardiac magnetic resonance and therapeutic value of immunosuppressive therapy

Table 3. The ESC diagnostic criteria for myocarditis heart failure

\begin{tabular}{|l|l|l|}
\hline Diagnostic & Test & Outcomes/Findings \\
\hline I. & ECG/Holter/Stress Test & $\begin{array}{l}\text { I-II degree AV-block or BBB, ST/T wave change, sinus arrest, ventricular tachycardia/fibrillation, AF, reduced R wave } \\
\text { height, wide QRS complex, abnormal Q waves, frequent premature beats, supraventricular tachycardia }\end{array}$ \\
\hline $\begin{array}{l}\text { II. } \\
\text { III. }\end{array}$ & Myocardiocytolysis markers & Functional/Structural abnormalities on cardiac \\
imaging & Elevated TnT/Tnl & $\begin{array}{l}\text { Unexplained LV/RV abnormalities; regional wall motion/global systolic dysfunction with/without ventricular dilatation, } \\
\text { with/without increased wall thickness, with/without pericardial effusion, with/without endocavity thrombi }\end{array}$ \\
IV. & Tissue characterization by CMR & Edema and/or LGE classical myocardial pattern \\
\hline
\end{tabular}

AV-Block: Atrioventricular Block; BBB: Bundle branch block; CMR: Cardiac Magnetic Resonance; ECG: Electrocardiogram; LGE: Late Gadolinium Enhancement; LV: Left Ventricle; RV: Right Ventricle. Adapted from European Society of Cardiology Working Group on Myocardial and Pericardial Diseases, 2013, p. 2643 [11]

who in the absence of active infection of myocardium would benefit from immunosuppression and/or immunomodulation $[9,11]$.

Electrocardiogram: The 2013 ESC pericardial and myocardial guidelines recommend ECG tests in all patients suspected with myocarditis. ECG is usually abnormal in myocarditis but the findings are both non-specific and non-sensitive [21,71,72]. Some ECG abnormalities are more suggestive of myocarditis than others are. $\mathrm{ST} / \mathrm{T}$ segment elevation in myocarditis is concave (but convex in MI) and diffuse without reciprocal changes. AV-block in mild ventricular dilatation could result from various causes including laminopathies but may suggest Lyme disease, cardiac sarcoidosis or GCM. ECG abnormalities have also been reported to have prognostic value in patients with myocarditis. QRS prolongation is an independent predictor of survival while Q-waves and repolarization abnormalities are unrelated to outcome or immunohistological features of inflammation [72].

Echocardiography: Echocardiography lacks pathognomonic features for diagnosis of myocarditis. However, it allows the assessment of cardiac chamber sizes and wall thickness as well as systolic and diastolic function in patients suspected with myocarditis. It is an important non-invasive imaging tool to exclude other causes of HF such as valvular heart disease or other cardiomyopathies such as hypertrophic or restrictive. Echocardiographic assessment is usually recommended before EMB procedure to rule out pericardial effusion and intra-cavitary thrombi, which occur in up to $25 \%$ of patients [10]. In addition, evaluation of different echocardiographic parameters has prognostic relevance in myocarditis patients. In fulminant myocarditis, patients have normal cardiac chamber sizes with increased septal thickness in the setting of acute myocardial edema while in acute myocarditis patients have marked LV dilatation and normal wall thickness [73]. The role of other echocardiographic techniques such as tissue Doppler or strain rate in the diagnosis of myocarditis have not been determined. The 2012 ESC guidelines recommends all patients with clinically suspected myocarditis should undergo standard transthoracic echocardiogram at presentation and during hospitalization in the case of worsening hemodynamics [11].

Cardiac magnetic resonance: Cardiac magnetic resonance (CMR) imaging is fast emerging as a valuable non-invasive imaging tool for tissue characterization of the myocardium to support the diagnosis of myocarditis. The timing of imaging in suspected patients usually depends on local availability and expertise but CMR is recommended in stable patients before EMB. CMR is not recommended in lifethreatening presentation where EMB is urgently indicated. Based on pre-clinical and clinical trials, the International Consensus Group on CMR in Myocarditis [74] proposed CMR diagnostic criteria (the Lake Louise Consensus Criteria) for myocarditis (Table 4).

Endomyocardial biopsy: Endomyocardial Biopsy (EMB) remains the gold standard for diagnosing myocarditis and type of inflammation (GCM, eosinophilic myocarditis or sarcoidosis). The Dallas criteria defines acute myocarditis by lymphocytic infiltrates in association with myocyte necrosis and borderline myocarditis by inflammatory infiltrates in the absence of demonstrated myocyte necrosis [75]. However, the Dallas criteria is limited by high inter-observer variability interpretation of biopsy samples especially borderline myocarditis and by inability to detect non-cellular inflammatory processes [56]. Immunohistochemistry is gaining acceptance in the diagnosis of myocarditis. The $2007 \mathrm{AHA} / \mathrm{ACC} / \mathrm{ESC}$ scientific statement on the role of EMB in the management of cardiovascular diseases gave EMB the highest level of recommendation in life-threatening presentations [76]. Performing EMB in the early course of myocarditis and taking multiple specimen has been recommended to improve diagnostic accuracy and reducing sampling error. At least three samples measuring 1-2 $\mathrm{mm}$ in size should be obtained from the RV or LV immediately put in $10 \%$ buffered formalin at room temperature for light microscopy and additional samples stored in RNA tubes at room temperature for viral PCR. Some myocarditis patients may present with exclusive LV or RV heart failure and the decision to choose either the LV or RV should rely on additional clinical information. To improve diagnostic accuracy, the use of large panel of monoclonal and polyclonal antibodies is mandatory to identify and characterize inflammatory infiltrates $[53,54]$. To exclude systemic infection, peripheral blood should evaluated with EMB viral quantification and replication [77]. Although its prognostic value has not been determined, EMB may be repeated is necessary to monitor response to etiology-specific therapy [77].

\section{Meta-analysis of diagnosis methods}

Myocarditis is an inflammatory disease of the myocardium and an importance cause of acute HF, SCD and DCM in young adults. Its diagnosis is complicated by great variability in clinical presentation and evolution, and the lack of reliable cardiac imaging tests [11,78]. While EMB remains the gold standard for a confirmatory diagnosis, its invasive nature and the risk of severe complications has limited its use in clinical settings [78]. Conversely, CMR imaging is gaining widespread use for assessing clinically suspected myocarditis due to its ability to detect myocardial inflammation, myocardial edema and fibrosis [79]. The Lake Louise Consensus Criteria suggests the combined utility of two or three CMR techniques (T1-weighted, T2-weighted and/or LGE) improves diagnostic accuracy [74]. The present meta-analysis seeks to compare diagnostic performance of CMR (sensitivity, specificity and accuracy) based on the Lake Louise Consensus Criteria in reference to EMB procedure. Search strategy, study selection, data extraction and analysis were performed based on PRISMA guidelines for systematic reviews and meta-analysis [80].

Study search and inclusion criteria: The search for studies on CMR and EMB diagnosis of myocarditis HF was conducted on online databases PubMed, EMBASE and Cochrane Central Register of Controlled Trials. The search strategy was based on a combination of the following key terms "cardiac magnetic resonance imaging" AND "myocarditis" OR "inflammatory cardiomyopathy" OR "inflammation 
Albakri A (2018) Myocarditis heart failure: A review of clinical status and meta-analyses of diagnostic performance of cardiac magnetic resonance and therapeutic value of immunosuppressive therapy

Table 4. Proposed CMR diagnostic criteria for myocarditis heart failure

In patients with clinical suspicion of myocarditis ${ }^{\text {a }}$, CMR findings are consistent with myocardial inflammation if at least two the following criteria are present:

1. Regional or global myocardial signal intensity in T2-weighted images ${ }^{\mathrm{b}}$;

2. Increased global myocardial early gadolinium enhancement ratio between myocardium and skeletal muscle in gadolinium-enhanced T1-weighted images ${ }^{\mathrm{c}}$ :

3. There is at least one focal lesion with non-ischemic regional distribution in inversion recovery-prepared gadolinium-enhanced T1-weighted images (LGE) ${ }^{\mathrm{d}}$

A CMR study is consistent with myocyte injury and/or scar caused by myocardial inflammation if Criterion 3 is present

A repeat CMR study 1-2 weeks after the initial CMR study is recommended if

1. None of the criteria are present, but the onset of symptoms has been very recent and there is strong clinical evidence for myocardial inflammation

2. One of the criteria is present

The presence of $L V$ dysfunction or pericardial effusion provides additional, supportive evidence for myocarditis

a: The clinical suspicion for active myocarditis should be based on the criteria listed in Table 2

b: Global signal intensity (SI) increase has to be quantified by an SI ratio of myocardium over skeletal muscle of $\geq 2.0$. If the edema is more subendocardial or transmural in combination with a co-localized ischemic (including the subendocardial layer) pattern of late gadolinium enhancement, acute myocardial infarction is more likely and should be reported

c: A global SI enhancement ratio of myocardium over skeletal muscle of $>4.0$ or an absolute myocardial enhancement of $>45 \%$ is consistent with myocarditis.

$\mathrm{d}$ : Images should be obtained at least $5 \mathrm{~min}$ after gadolinium injection; foci typically exclude the subendocardial layer, are often multifocal, and involve the sub-epicardium. If the late gadolinium enhancement pattern clearly indicates myocardial infarction and is co-localized with a transmural regional edema, acute myocardial infarction is more likely and should be reported

Adapted from International Consensus Group on CMR in Myocarditis [74]

dilated cardiomyopathy" AND "endomyocardial biopsy". Additional studies were obtained from manual search of bibliographies of included studies and review articles. The search was restricted to human studies. There was no restriction on publication language and time.

Studies were eligible for inclusion if they met the following criteria: (a) were randomized controlled prospective or retrospective clinical trials; (b) recruited patients suspected with myocarditis or inflammatory DCM with reduced ejection fraction; (c) evaluated diagnostic performance of CMR using EMB as reference standard; and (d) provided sufficient data to compared diagnostic performance of CMR against EMB. Case series and studies that did not use original data such as duplicate studies, review articles, and editorials were excluded. All published articles investigating diagnostic performance of CMR with reference EMB were identified. Studies the categorized patients in groups, each group was analyzed separately.

Two reviewers screened titles and abstract for potential studies, and in the second step, all potentially suitable articles were reviewed for final eligibility. Duplicates were identified and excluded. Full-text of all included studies were obtained and two investigators independently assessed study eligibility and extracted data. The following details were recorded from each study: study characteristics (first author, publication year, and study design), patient characteristics (number, mean age and proportion of male) and diagnostic performance (sensitivity, specificity and accuracy) as summarized in Table 5.

Study characteristics and outcomes: The initial online search and screening of bibliographies and review articles yielded 271 articles. After screening titles and abstracts, 22 studies were selected for full text screening. Finally, six studies meeting the eligibility criteria were included in this meta-analysis [81-86]. The total number of patients enrolled in the six studies were 474 . The patients were relatively young (mean age $=47$ years) with a majority being of the male gender $(72 \%)$. The performance of CMR in the diagnosis of myocarditis HF was assessed using three CMR techniques in reference to EMB: T1-W global relative enhancement (gRE), T2-W edema ratio of the myocardium (ER), and late gadolinium enhancement (LGE) in contrast CMR imaging and Lake Louise Criteria (LLC). One study grouped patients into two (acute and chronic myocarditis) [86] and another into three based on myocarditis pattern (infarct-like, cardiomyopathic and arrhythmic patterns) [84]. Each group was analyzed separately. The most common diagnosis of EMB was myocarditis (36.0\% [83]; 52.0\% [85]; 58.0\% [81]; 62.8\% [82]). Weighted mean revealed sensitivity, specificity and accuracy for LGE (48\%, $72 \%$ and $61 \%)$, gRE $(68 \%, 65 \%$ and $64 \%)$, ER $(69 \%, 72 \%$ and
$72 \%)$ and LLC (69\%, 56\% and 67\%). Our findings suggest that CMR imaging based on LLC and its three components (LGE, gRE and ER) are moderately accurate in the diagnosis of myocarditis HF in clinically suspected patients. The findings also suggests EMB remains the gold standard for confirmatory diagnosis of myocarditis and a need to develop newer parameters or imaging technique to improve CMR diagnostic performance.

Discussion: Despite various imaging modalities available today, diagnostics of myocarditis $\mathrm{HF}$ is a demanding task and remains diagnosis of exclusion. The ESC recommends EMB with immunohistochemistry and PCR (for viral genomes) for diagnosing myocarditis as well as providing additional insight about underlying etiology and pathogenic mechanisms $[11,84,87]$. However, EMB is invasive, is associated with increased risk of complication and is only considered first choice method only in specialized health centers with the experience and expertise in performing the procedure [87]. For these reasons, CMR imaging based on the LLC is becoming the criterion standard for non-invasive diagnosis of myocarditis. It allows the identification of the hallmarks of myocardial inflammation (edema, fibrosis, and hyperemia), and is able to characterize tissue and to assess regional and global biventricular function [74]. However, current research evidence on the diagnostic performance of CMR rely on small-scale studies, which have inconsistent findings. In the present meta-analysis, CMR has a moderate diagnostic performance relative to EMB in patients with a clinical suspicion of myocarditis.

Moderate accuracy of CMR parameters as defined by the LLC have also been described elsewhere. The three CMRI parameters LGE, gRE and ER investigated in the present study provide surrogate measures for three common histopathological features of myocardial inflammation - myocardial edema, hyperemia and fibrosis, which may have lower sensitivity and specificity for myocarditis compared to other cardiovascular diseases [74,78]. In myocarditis, LGE in contrast CMR imaging, which reflects myocardial necrosis and fibrosis has been shown to be non-specific and non-sensitive because necrosis and fibrosis could also be observed in many other cardiac diseases with myocardial injury and remodeling such as cardiac sarcoidosis and nonischemic cardiomyopathy $[88,89]$. In addition, patients with moderate myocarditis have insignificant myocardial necrosis and fibrosis that LGE may not detect [89]. T2-W edema ratio reflects the extent of myocardial edema is also non-specific since it is a feature observed in other cardiac diseases with myocardial interstitial injury [91]. Low signal-to-noise ratio also limits the diagnostic accuracy of ER [92]. Lastly, T1-W gRE 
Albakri A (2018) Myocarditis heart failure: A review of clinical status and meta-analyses of diagnostic performance of cardiac magnetic resonance and therapeutic value of immunosuppressive therapy

Table 5. Characteristics of randomized trials on CMR diagnosis performance

\begin{tabular}{|c|c|c|c|c|c|c|c|c|c|c|c|c|c|c|c|c|}
\hline \multirow{2}{*}{$1^{\text {st }}$ Author [Ref\#] } & \multirow{2}{*}{ Year } & \multirow{2}{*}{$\begin{array}{c}\text { No. of } \\
\text { Patient (n) }\end{array}$} & \multirow{2}{*}{$\begin{array}{c}\text { Mean } \\
\text { Age } \\
\text { (yrs.) }\end{array}$} & \multirow{2}{*}{$\begin{array}{c}\text { Male } \\
(\%)\end{array}$} & \multicolumn{4}{|c|}{ Sensitivity (\%) } & \multicolumn{4}{|c|}{ Specificity (\%) } & \multicolumn{4}{|c|}{ Accuracy (\%) } \\
\hline & & & & & LGE & gRE & ER & LLC & LGE & gRE & ER & LLC & LGE & gRE & ER & LLC \\
\hline Gutberlet et al. [81] & 2008 & 83 & 45 & 66 & 27 & 62 & 67 & 81 & 80 & 86 & 69 & 49 & 49 & 72 & 68 & 68 \\
\hline Lurz et al. [82] & 2013 & 132 & 45 & 79 & 69 & 74 & 56 & 76 & 46 & 33 & 65 & 54 & 61 & 60 & 59 & 68 \\
\hline Sramko et al. [83] & 2013 & 42 & 43 & 71 & 47 & 87 & 40 & 67 & 89 & 44 & 96 & 85 & 74 & 60 & 76 & 79 \\
\hline \multirow{3}{*}{ Francone et al. [84] } & \multirow{3}{*}{2014} & 21 & 45 & 62 & NR & NR & NR & 80 & NR & NR & NR & NR & NR & NR & NR & NR \\
\hline & & 21 & 53 & 86 & NR & NR & NR & 57 & NR & NR & NR & NR & NR & NR & NR & NR \\
\hline & & 15 & 53 & 67 & NR & NR & NR & 40 & NR & NR & NR & NR & NR & NR & NR & NR \\
\hline Bohnen et al. [85] & 2015 & 31 & 51 & 77 & NR & NR & 94 & 88 & NR & NR & 60 & NR & NR & NR & 77 & NR \\
\hline \multirow{2}{*}{ Lurz et al. [86] } & \multirow{2}{*}{2016} & 61 & 40 & 72 & NR & 88 & 85 & 66 & NR & 67 & 68 & 47 & NR & 81 & 80 & 59 \\
\hline & & 68 & 46 & 72 & NR & 27 & 71 & 64 & NR & 94 & 72 & 47 & NR & 45 & 73 & 59 \\
\hline
\end{tabular}

ER: T2-weighed edema ratio of the myocardium; gRE: T1-weighed global relative enhancement; LGE: Late Gadolinium Enhancement in contrast CMRI; LLC: Lake Louise Criteria; NR: Not Reported

reflect myocardial hyperemia is also non-specific to myocarditis [92]. Signal intensity of skeletal muscle is used for the normalization of the gRE ratio, and in the presence of skeletal muscle disease, gRE may give false negative [93].

Whereas a recent International Consensus Group on Cardiovascular MR in Myocarditis suggests combining at least two CMR parameters improves diagnostic accuracy, the present findings still show moderate diagnostic performance. The findings suggest the need for developing novel CMR parameters and/or imaging techniques to improve the accuracy of non-invasive diagnosis of myocarditis. However, our analysis may be limited with small number of studies and patients as well as significant heterogeneity among individual studies with regard to duration of symptoms, presence of co-morbidities and CMI protocols used in imaging contributing to heterogeneity.

\section{Clinical management}

Ideally, clinical management of strategies for myocarditis HF should target the causal pathophysiology but the effect of a specific etiology-focused therapy has only been confirmed in a few studies on inflammatory heart diseases such as GCM and sarcoidosis. Since patients with myocarditis have a high incidence of impaired LV function, evidence-based HF therapy is strongly recommended to these patients [9]. The primary target of myocarditis treatment are optimal care of arrhythmias and HF, and etiologic agents.

\section{Treatment strategies}

Three strategies have been recommended for treating patients diagnosed with myocarditis HF: (a) HF therapy; (b) Immunomodulatory therapy; and (c) Immunosuppressive therapy [11].

Heart failure therapy: Myocarditis patients with hemodynamically unstable HF should receive prompt evidence-based HF medication according to the current ESC HF guidelines [94] in intensive care units with respiratory and mechanical cardio-pulmonary support facilities. Patients with acute or fulminant myocarditis presenting with cardiogenic shock and severe LV or RV dysfunction, mechanical circulatory support device or extracorporeal membrane oxygenation (ECMO) is recommended as a bridge to recovery or cardiac transplantation [95-98]. In patients suspected myocarditis who are asymptomatic or mildly symptomatic based on clinical suspicion criteria (Table 2), hospital admission and clinical monitoring are recommended until the establishment of a definite diagnosis. Monitoring is important since myocarditis can develop rapidly into a cardio-pulmonary emergency (lethal arrhythmias or severe heart block) despite preserved systolic function [95]. Exercise testing is contraindicated due to increased risk of arrhythmias [11].
Recommendation medications for myocarditis patients with hemodynamically stable HF are diuretics, angiotensin-converting enzyme inhibitor (ACE-I) or angiotensin receptor blocker (ARB). The 2012 ESC HF guidelines recommend consideration of additional aldosterone antagonist therapy for patients with persistent HF symptoms despite optimal clinical management [99]. However, weaning procedures of HF therapy after recovery of ventricular function remain undefined. Non-steroidal anti-inflammatory drugs are efficacious in acute pericarditis patients but experimental myocarditis animal models document increased risk of mortality $[59,100]$ while clinical data in humans are inconclusive [11]. No recommendations for specific therapy for myocarditis patients with arrhythmias but strategies adopted should be consistent with the current ESC HF guidelines [94]. Temporary pacing may be considered in patients with complete AV-block. The utility of implanted cardioverter defibrillator remains controversial since myocarditis may heal completely. However, wearable cardioverter defibrillator in myocarditis patients with severe ventricular arrhythmias (AF or ventricular tachycardia) could solve the transient nature of myocarditis [101]. In the acute phase of myocarditis, in addition to medication, patients should avoid physical activity until the disease has completely healed [102-103]. Despite age, gender, severity of symptoms and therapeutic regime, athletes should be excluded from sporting activity until the resolution of clinical presentation and followup clinical indication [103].

Immunomodulatory therapy: Immunomodulatory therapy for patients with myocarditis HF may include antiviral, intravenous immunoglobulin and immunoadsorption therapies [11]. The rationale for considering antiviral therapy is based on the knowledge that the most common causes of myocarditis are secondary to viral infection [9]. However, at present, there are no proven antiviral therapies for the treatment of enteroviral infections. Vaccines are a promising option in the future. Acyclovir, gancyclovir, and valacyclovir may be considered in herpes virus infection but its efficacy is unproven in myocarditis [104]. Primary evidence on interferon-beta treatment suggests it eliminates enteroviral and adenoviral infections in patients with impaired LV function as well as improves in New York Heart Association (NYHA) functional class [105]. If the use of specific antiviral therapies is considered, infectious disease specialists should be involved [11].

Intravenous immunoglobulin (IVIG) in high doses have been shown to modulate immune and inflammatory response [11]. It has been used in a number of systemic autoimmune disorders and has been associated with improved LV ejection fraction in chronic overt HF but ineffective in recent onset of DCM 15\% with biopsy-proven myocarditis of unspecified cause [106]. Since IVIG has no adverse side effects, it may be considered in patients with viral and autoimmune myocarditis 
Albakri A (2018) Myocarditis heart failure: A review of clinical status and meta-analyses of diagnostic performance of cardiac magnetic resonance and therapeutic value of immunosuppressive therapy

(especially autoantibody-mediated) that is refractory to conventional HF therapy [9]. However, since the use of IVIG in myocarditis lacks multi-center randomized trials, its specific recommendations to patients with myocarditis HF are lacking.

Immunoadsorption (IA) targets to eliminate anti-cardiac antibodies against various cardiac call proteins, which have been found in patients with DCM and myocarditis. The removal of circulating antibodies by IA in DCM patients has been shown to improve cardiac function [107] and humoral markers of HF severity such as exercise capacity and natriuretic peptides $[108,109]$. IA has also been associated with improvements in hemodynamic parameters such as stroke volume index and systemic vascular resistance [110] and decreased myocardial inflammation [107]. The current evidence suggests IA may be a promising treatment for patients with autoimmune myocarditis HF or DCM. However, therapeutic value of IA in myocarditis has not been determined but ongoing small-scale randomized controlled trials in Europe exploring the use of IA and its value in myocarditis [11].

Immunosuppressive therapy: Immunosuppressive therapy (cyclosporine, prednisolone, azathioprine) in acute myocarditis have had inconclusive findings. In patients with chronic DCM, azathioprine and prednisolone improved LV function and NYHA functional class [57,110]. In the Immunosuppressive Therapy in Patients with Virus Negative Inflammatory Cardiomyopathy (TIMIC) study, prednisone and azathioprine caused significant improvement in LV ejection fraction and a decrease LV dimensions [111]. The ESC [11] recommends immunosuppressive therapy should only be started after excluding active infection by PCR on EMB. Immunosuppression may also be considered in proven autoimmune (infection negative) forms of myocarditis HF with no contraindications including GCM, cardiac sarcoidosis and myocarditis associated with known extra-cardiac autoimmune disease. Steroid therapy is indicated in cardiac sarcoidosis with LV dysfunction and/or arrhythmias and in toxic myocarditis with $\mathrm{HF}$ and/or arrhythmias. Immunosuppression requires follow-up EMB to guide the intensity and length therapy [11].

Meta-analysis of immunomodulatory and immunosuppressive therapies

Myocarditis HF lacks curative therapy. Current clinical management strategies largely focus on relief of HF symptoms and concomitant adverse events using traditional HF therapies. Since deleterious inflammatory reaction to viral infection induces myocardial dysfunction, therapies targeting immunomodulation may have potentially beneficial outcomes [106-109]. In addition, long-term consequences of myocarditis have been associated with the activation of cellular and humoral auto-immunity suggesting potential benefits of immunosuppressive therapy [17,110-111]. However, the current research evidence on therapeutic value of immunomodulation and immunosuppression therapies for patients with myocarditis are inconclusive. This meta-analysis pools together data from relevant clinical trials to determine clinical benefits of using immunomodulatory and immunosuppressive therapies in patients with myocarditis HF.

Study search and inclusion criteria: Studies investigating clinical benefits of immunomodulatory or immunosuppressive therapies on patients with myocarditis HF were searched from online databases PubMed, EMBASE and Cochrane Central Register of Controlled Trials. The search strategy was based on a combination of the following key search terms: "myocarditis" OR "inflammatory cardiomyopathy" AND "immunomodulatory" OR "immunosuppressive". Bibliographies of included studies and review articles were also searched to identify additional articles missed by the online search. Eligibility criteria for inclusion were the studies; (a) enrolled patients with myocarditis or inflammatory cardiomyopathy; (b) randomized or quasi-randomized patients into treatment or placebo groups; (c) compared immunomodulatory or immunosuppressive with placebo or conventional therapies; and (d) reported effect on cardiac function..

Two reviewers independently assessed the studies for eligibility and inclusion and disagreements resolved through consensus. The following details were recorded from each study included: first author, publication year, number of patients enrolled, mean age and proportion of male patients, type of therapy and outcomes of therapy (Table 6). The primary efficacy outcomes was LVEF measured by echocardiography or scintigraphy, NYHA and viral clearance and resolution of inflammatory filtrate. Continuous data was reported using mean and standard deviation. Treatment effects for dichotomous outcomes were expressed as odds ratio with $95 \%$ CI. Pooled effect was calculated using fixed effect model and random effect model. Statistical significance was defined as $\mathrm{p}<0.01$ or $\mathrm{I}^{2}>25 \%$.

Study characteristics and outcomes: The initial search identified 206 potential studies. After title, abstract and full-text-screening against the inclusion criteria, six studies were included in this metaanalysis [20,57,111-114]. The combined patient population was 471 with biopsy-proved myocarditis or inflammatory cardiomyopathy with demonstrated LV dysfunction randomized into treatment group $(\mathrm{n}=$ $235)$ and control or placebo group $(n=236)$. Patients were relatively young (mean age $=42$ years) with a predominant male population (68\%). The main drugs investigated were prednisone, azathioprine or cyclosporine, and interferon-alpha or thymomodulin. The main clinical endpoints studied were improvement of LVEF $\geq 5 \%$ and cases adverse clinical endpoints defined as death or cardiac transplantation. Our pooled analysis reveals that treatment of myocarditis HF using

Table 6. Characteristics of randomized trials on immunosuppressive therapy

\begin{tabular}{|c|c|c|c|c|c|c|c|c|c|c|c|}
\hline \multirow{2}{*}{$\begin{array}{c}1^{\text {st }} \text { Author } \\
\text { [Ref\#] }\end{array}$} & \multirow{2}{*}{ Year } & \multicolumn{2}{|c|}{ Patient Size } & \multirow{2}{*}{ Age (yrs.) } & \multirow{2}{*}{ Male (\%) } & \multirow{2}{*}{ Drug } & \multicolumn{2}{|c|}{ Improved LVEF (n) } & \multicolumn{2}{|c|}{ Died/HTx (n) } & \multirow{2}{*}{ FUP (Months) } \\
\hline & & Trmnt & Ctrl & & & & Trmnt & Ctrl & Trmnt & Ctrl & \\
\hline $\begin{array}{l}\text { Latham et al. } \\
\text { [112] }\end{array}$ & 1989 & 12 & 40 & 41 & 81 & Prednisone & NR & NR & 11 & 11 & 24 \\
\hline $\begin{array}{l}\text { Parrillo et al. } \\
{[111]}\end{array}$ & 1989 & 49 & 52 & 43 & NR & Prednisone & 5 & 9 & 9 & 5 & 15 \\
\hline Mason et al. [20] & 1995 & 64 & 47 & 43 & 58 & $\begin{array}{c}\text { Azathioprine/ } \\
\text { cyclosporine+ prednisone }\end{array}$ & 54 & 35 & NR & NR & 24 \\
\hline Miric et al. [113] & 1996 & 26 & 12 & $19 / 54$ & 61 & $\begin{array}{l}\text { Interferon-alpha or } \\
\text { thymomodulin }\end{array}$ & 21 & 8 & 2 & 3 & 24 \\
\hline $\begin{array}{l}\text { Wojnicz et al. } \\
{[57]}\end{array}$ & 2001 & 41 & 43 & 39 & 82 & Azathioprine + prednisone & 24 & 11 & 8 & 8 & 24 \\
\hline $\begin{array}{l}\text { Frustaci et al. } \\
{[114]}\end{array}$ & 2009 & 43 & 42 & 44 & 60 & Azathioprine + prednisone & 38 & 7 & 0 & 2 & 24 \\
\hline
\end{tabular}


Albakri A (2018) Myocarditis heart failure: A review of clinical status and meta-analyses of diagnostic performance of cardiac magnetic resonance and therapeutic value of immunosuppressive therapy

immunosuppressive therapy compared to conventional HF therapies has a short-term benefit in improving LVEF (OR: 3.2, 95\% CI: 2.095.05, $\mathrm{p}<0.001, \mathrm{I}^{2}=65.8 \%$ ) (Figure 2 ) but there was no evidence of significant effect on protection against all-cause death and/or cardiac transplantation (OR: 1.7, 95\% CI: 0.9-3.1, $\mathrm{p}=0.08, \mathrm{I}^{2}=69.7 \%$ ) (Figure $3)$.

\section{Discussion}

Current recommended treatment of myocarditis $\mathrm{HF}$ and inflammatory DCM largely focuses on supportive care with evidencebased and guideline-directed treatment of HF and arrhythmias $[11,99]$. Although the suppression of autoimmune response in chronic myocarditis has been considered potentially beneficial, limited availability of RCTs testing this hypothesis reflects insufficient evidence for therapeutic benefits of immunosuppressive therapy in these patients. In the present meta-analysis, we identified six studies assessing the effect of immunosuppressive or immunomodulatory therapy but individual studied investigated different treatment strategies (immunosuppressive single or combination therapy) thus analysis of pooled treatment effect was not feasible. We instead chose to investigate treatment effect on surrogate endpoints (improvement in LVEF function defined by echocardiography, and death or cardiac transplantation) in patients with EMB-proven myocarditis HF.

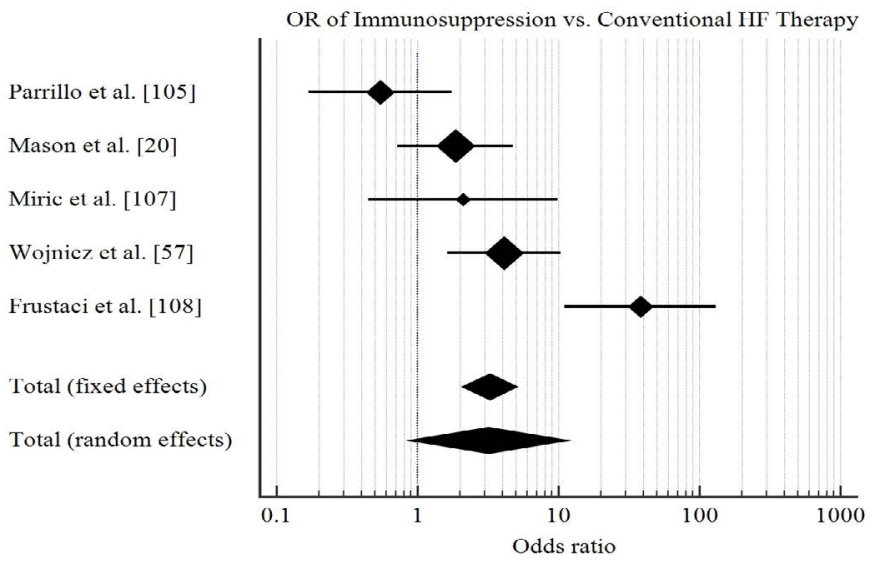

Figure 2. Forrest plot of effect of immunosuppression on ejection fraction

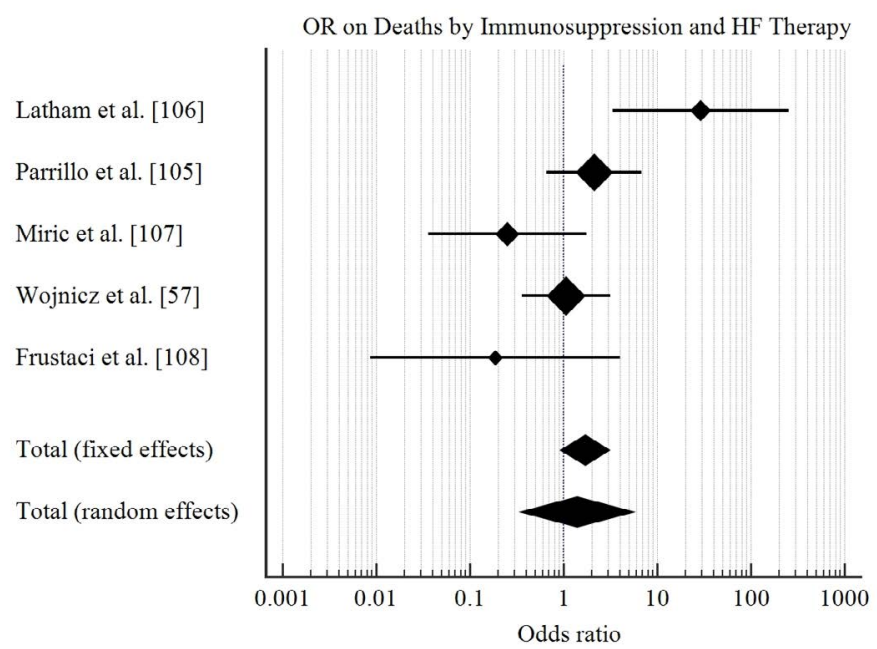

Figure 3. Forrest plot of effect of immunosuppression on deaths and transplantation
In our analysis, there is no evidence that immunosuppressive therapy for myocarditis patients with HF will provide a greater protective effect against death or cardiac transplantation compared to the conventional HF therapy. Although in the short-term, immunosuppressive therapy may induce a mild improvement in LV function (mildly increased LVEF), the effect is not sustained in the long-term. The findings support that cardiac transplantation may be the only long-term treatment strategy that can prolong survival in patients with myocarditis HF. Previous meta-analysis on immunomodulation therapy [116] and immunosuppressive therapy [117] provide similar findings, reporting that immunomodulatory and immunosuppressive therapies have a non-significant effect on cardiac function, all cause death and the need for cardiac transplantation.

However, for patients with histologically proven infection-negative myocarditis, a combination of immunosuppressive therapies might be clinically beneficial [117]. In a single-center study, Frustaci et al. [114] suggested beneficial effect of combining steroid and azathioprine therapy in patients with virus-negative myocarditis. The ESC also recommends immunosuppressive therapy on infection negative patients and followup EMB to guide treatment intensity and duration [11]. However, additional clinical trials with long-term follow-up and consideration of treatment intensity and duration are needed to determine therapeutic benefits of immunomodulatory and immunosuppressive therapies for high-risk myocarditis patients presenting with major clinical syndromes (severe HF and/or life threatening arrhythmias) who are refractory to conventional HF therapies.

\section{Conclusion}

Myocardial heart failure a cardiac syndrome resulting from acute or chronic inflammation of the myocardium produced by infectious agents or drugs and toxins with LV dilatation and depressed ejection fraction. It is more predominant among young adults. It has a predominant viral etiology and less frequently bacterial, fungi and parasites, and non-infectious causes such as systemic autoimmune responses and drug-induced hypersensitivity. Pathophysiologic mechanisms are triphasic. In the initial acute phase, viral infection and replication induces innate immune response. In the subacute phase, myocardial damage induces autoantibodies and autoimmune cells through epitope spreading or molecular mimicry. In the chronic phase, low-grade viral persistence and sustained inflammation induces myocardial remodeling leading to ventricular dilatation and contractile dysfunction and ultimately heart failure. It has varied modes of clinical manifestations in its clinical course ranging from asymptomatic and non-specific systemic symptoms to life threatening cardiogenic shock and ventricular arrhythmias making diagnosis-based on symptoms impossible. Confirmatory diagnosis is challenging because of diversity of symptoms and limited utility of endomyocardial biopsy considered the gold standard for diagnosing myocarditis HF. Integrated evaluation of clinical and instrumental non-invasive tests (biomarkers and virus serology, ECG, echocardiography and cardiac magnetic resonance imaging is fundamental to identify suspected myocarditis HF. However, histologic and immunohistochemically analysis of myocardial tissue samples obtained with an endomyocardial biopsy established diagnosis. Clinical management targets treating HF using conventional HF therapies and the underlying etiology using immunomodulatory or immunosuppressive therapy.

\section{References}

1. Cubero JS, Rivera LA, Moral RP, Melchor LS (2004) Heart failure: etiology and approach to diagnosis. Revista espanola de cardiologia 57: 250-259. [Crossref] 
Albakri A (2018) Myocarditis heart failure: A review of clinical status and meta-analyses of diagnostic performance of cardiac magnetic resonance and therapeutic value of immunosuppressive therapy

2. Haydock PM, Cowie MR (2010) Heart failure: classification and pathophysiology. Medicine 38: 467-472. [Crossref]

3. Maron BJ, Towbin JA, Thiene G, Antzelevitch C, Corrado D et al. (2006) Contemporary definitions and classification of the cardiomyopathies: an American heart association scientific statement from the council on clinical cardiology, heart failure and transplantation committee; quality of care and outcomes research and functional genomics and translational biology interdisciplinary working groups; and council on epidemiology and prevention. Circ 113: 1807-1816. [Crossref]

4. Elliott P, Andersson B, Arbustini E, Bilinska Z, Cecchi F et al. (2007) Classification of the cardiomyopathies: a position statement from the European Society of Cardiology Working Group on Myocardial and Pericardial Diseases. Eur Heart J 29: 270-276. [Crossref]

5. Cooper Jr LT, Keren A, Sliwa K, Matsumori A, Mensah GA (2014) The global burden of myocarditis: part 1: a systematic literature review for the Global Burden of Diseases, Injuries, and Risk Factors 2010 study. Global heart 9: 121-129. [Crossref]

6. Fung G, Luo H, Qiu Y, Yang D, McManus B (2016) Myocarditis. Circ Res 118: 496514. [Crossref]

7. Richardson P (1996) Report of the 1995 World Health Organization/International Society and Federation of Cardiology. Task force on the definition and classification of cardiomyopathies. Circ 93: 841-842. [Crossref]

8. Heymans S, Eriksson U, Lehtonen J, Cooper LT (2016) The quest for new approaches in myocarditis and inflammatory cardiomyopathy. $\mathrm{J} \mathrm{Am} \mathrm{Coll} \mathrm{Cardiol} \mathrm{68:} \mathrm{2348-2364.}$ [Crossref]

9. Kindermann I, Barth C, Mahfoud F, Ukena C, Lenski M et al. (2012) Update on myocarditis. J Am Coll Cardiol 59: 779-792. [Crossref]

10. Blauwet LA, Cooper LT (2010) Myocarditis. Prog. Cardiovasc. Dis 52: 274-288. [Crossref]

11. Caforio AL, Pankuweit S, Arbustini E, Basso C, Gimeno-Blanes J et al. (2013) Current state of knowledge on aetiology, diagnosis, management, and therapy of myocarditis: a position statement of the European Society of Cardiology Working Group on Myocardial and Pericardial Diseases. Eur Heart J 34: 2636-2648. [Crossref]

12. Miller T (2015) Global, regional, and national incidence, prevalence, and years lived with disability for 301 acute and chronic diseases and injuries in 188 countries, 19902013: a systematic analysis for the Global Burden of Disease Study 2013. The Lancet 86: 743-800. [Crossref]

13. Maron BJ, Levine BD, Washington RL, Baggish AL, Kovacs RJ et al. (2015) Eligibility and disqualification recommendations for competitive athletes with cardiovascular abnormalities: task force 2: pre-participation screening for cardiovascular disease in competitive athletes: a scientific statement from the American Heart Association and American College of Cardiology. J Am Coll Cardiol 66: 2356-2361. [Crossref]

14. Karjalainen J, Heikkila J (1999) Incidence of three presentations of acute myocarditis in young men in military service. A 20-year experience Eur Heart 20: 1120-1125. [Crossref]

15. Wakafuji S, Okada R (1986) Twenty Year Autopsy Statistics of Myocarditis Incidence in Japan: The 10th conference on prevention for rheumatic fever and rheumatic heart disease. Jpn Circ J 50: 1288-1293. [Crossref]

16. Carniel E, Sinagra G, Bussani R, Di AL, Pinamonti B, Lardieri G et al. (2004) Fata myocarditis: morphologic and clinical features. Ital Heart J 5: 702-706. [Crossref]

17. Kyto V, Saraste A, Voipio-Pulkki LM, Saukko P (2007) Incidence of fatal myocarditis: a population-based study in Finland. Am J Epidemiol 165: 570-574. [Crossref]

18. Gravanis MB, Sternby NH (1991) Incidence of myocarditis. A 10-year autopsy study from Malmo, Sweden. Arch Pathol Lab Med 115: 390-392. [Crossref]

19. Doolan A, Langlois N, Semsarian C (2004) Causes of sudden cardiac death in young Australians. Med J Aust 180: 110-112. [Crossref]

20. Mason JW, O'connell JB, Herskowitz A, Rose NR, McManus BM et al. (1995) A clinical trial of immunosuppressive therapy for myocarditis. $N$ Engl J Med 333: 269275. [Crossref]

21. Caforio AL, Calabrese F, Angelini A, Tona F, Vinci A et al. (2007) A prospective study of biopsy-proven myocarditis: prognostic relevance of clinical and aetiopathogenetic features at diagnosis. Eur Heart $J$ 28: 1326-1333. [Crossref]

22. Magnani JW, Danik HJ, Dec Jr GW, DiSalvo TG (2006) Survival in biopsy-proven myocarditis: a long-term retrospective analysis of the histopathologic, clinical, and hemodynamic predictors. Am Heart $J$ 151: 463-470. [Crossref]

23. Lyden DC, Olszewski J, Feran M, Job LP, Huber SA (1987) Coxsackievirus B-3induced myocarditis. Effect of sex steroids on viremia and infectivity of cardiocytes. Am J Pathol 126: 432-438. [Crossref]
24. Frisancho-Kiss S, Coronado MJ, Frisancho JA, Lau VM, Rose NR et al. (2009) Gonadectomy of male BALB/c mice increases Tim-3+ alternatively activated M2 macrophages, Tim- $3+\mathrm{T}$ cells, Th2 cells and Treg in the heart during acute coxsackievirus-induced myocarditis. Brain Behav Immun 23: 649-657. [Crossref]

25. Cooper Jr LT, Berry GJ, Shabetai R (1997) Idiopathic giant-cell myocarditis—natural history and treatment. $N$ Engl J Med 336: 1860-1866. [Crossref]

26. Fenoglio Jr JJ, Ursell PC, Kellogg CF, Drusin RE, Weiss MB (1983) Diagnosis and classification of myocarditis by endomyocardial biopsy. $N$ Engl J Med 308: 12-18. [Crossref]

27. Shen WK, Edwards WD, Hammill SC, Bailey KR, Ballard DJ et al. (1995) Sudden unexpected nontraumatic death in 54 young adults: a 30 -year population-based study. $J$ Am Coll Cardiol 76: 148-152. [Crossref]

28. Passarino G, Burlo P, Ciccone G, Comino A (1997) Prevalence of myocarditis at autopsy in Turin, Italy. Arch Pathol Lab Med 121: 619-622. [Crossref]

29. Rasten-Almqvist P, Eksborg S, Rajs J (2002) Myocarditis and sudden infant death syndrome. Apmis 110: 469-480. [Crossref]

30. Topaz ON, Edwards JE (1985) Pathologic features of sudden death in children, adolescents, and young adults. Chest 87: 476-482. [Crossref]

31. Neuspiel DR, Kuller LH (1985) Sudden and unexpected natural death in childhood and adolescence. Jama.254: 1321-1325. [Crossref]

32. Towbin JA, Lowe AM, Colan SD, Sleeper LA, Orav EJ et al. (2006) Incidence, causes, and outcomes of dilated cardiomyopathy in children. Jama 296: 1867-1876. [Crossref]

33. Rahman JE, Helou EF, Gelzer-Bell R, Thompson RE, Kuo C et al. (2004) Noninvasive diagnosis of biopsy-proven cardiac amyloidosis. J Am Coll Cardiol 43: 410-415. [Crossref]

34. Frustaci A, Verardo R, Caldarulo M, Acconcia MC, Russo MA et al. (2007) Myocarditis in hypertrophic cardiomyopathy patients presenting acute clinical deterioration. Eur Heart J 28: 733-740. [Crossref]

35. Basso C, Corrado D, Marcus FI, Nava A, Thiene G (2009) Arrhythmogenic right ventricular cardiomyopathy. The Lancet 373: 1289-1300. [Crossref]

36. Andreoletti L, Leveque N, Boulagnon C, Brasselet C, Fornes P (2009) Viral causes of human myocarditis. Arch Cardiovasc Dis 102: 559-568. [Crossref]

37. Kuhl U, Pauschinger M, Seeberg B, Lassner D, Noutsias M et al. (2005) Viral persistence in the myocardium is associated with progressive cardiac dysfunction. Circ 112: 1965-1970. [Crossref]

38. Bowles NE, Ni J, Kearney DL, Pauschinger M, Schultheiss HP, McCarthy R et al. (2003). Detection of viruses in myocardial tissues by polymerase chain reaction: evidence of adenovirus as a common cause of myocarditis in children and adults. $J \mathrm{Am}$ Coll Cardiol 42: 466-472. [Crossref]

39. Kuhl U, Pauschinger M, Noutsias M, Seeberg B, Bock T et al. (2005) High prevalence of viral genomes and multiple viral infections in the myocardium of adults with "idiopathic" left ventricular dysfunction. Circ 111: 887-893. [Crossref]

40. Baruteau AE, Boimond N, Ramful D (2010). Myocarditis associated with 2009 influenza A (H1N1) virus in children. Cardiol Young 20: 351-352. [Crossref]

41. Pauschinger M, Bowles NE, Fuentes-Garcia FJ, Pham V, Kühl U et al. (1999) Detection of adenoviral genome in the myocardium of adult patients with idiopathic left ventricular dysfunction. Circ 99: 1348-1354. [Crossref]

42. Matsumori A, Yutani C, Ikeda Y, Kawai S, Sasayama S (2000) Hepatitis C virus from the hearts of patients with myocarditis and cardiomyopathy. Lab Invest 80: 1137-1142. [Crossref]

43. Omura T, Yoshiyama M, Hayashi T, Nishiguchi S, Kaito M et al. (2005) Core protein of hepatitis C virus induces cardiomyopathy. Circ Res 96: 148-150. [Crossref]

44. Sudano I, Spieker LE, Noll G, Corti R, Weber R, Lüscher TF (2006) Cardiovascular disease in HIV infection. Am Heart J 151: 1147-1155. [Crossref]

45. Chimenti C, Russo A, Pieroni M, Calabrese F, Verardo R et al. (2004) Intramyocyte detection of Epstein-Barr virus genome by laser capture microdissection in patients with inflammatory cardiomyopathy. Circ 110: 3534-3539. [Crossref]

46. Ellis NM, Kurahara DK, Vohra H, Mascaro-Blanco A, Erdem G et al. (2010) Priming the immune system for heart disease: a perspective on group A streptococci. $J$ Infect Dis 202: 1059-1067. [Crossref]

47. Karatolios K, Maisch B, Pankuweit S (2015) Suspected inflammatory cardiomyopathy. Herz 40: 91-95. [Crossref] 
Albakri A (2018) Myocarditis heart failure: A review of clinical status and meta-analyses of diagnostic performance of cardiac magnetic resonance and therapeutic value of immunosuppressive therapy

48. Marin-Neto JA, Cunha-Neto E, Maciel BC, Simoes MV (2007) Pathogenesis of chronic Chagas heart disease. Circ 115: 1109-1123. [Crossref]

49. Haas SJ, Hill R, Krum H, Liew D, Tonkin A et al. (2007). Clozapine-associated myocarditis. Drug Safety 30: 47-57. [Crossref]

50. Cook SC, Ferguson BA, Cotes RO, Heinrich TW, Schwartz AC (2015) Clozapineinduced myocarditis: prevention and considerations in rechallenge. Psychosomatics 56: 685-690. [Crossref]

51. Engler RJ, Nelson MR, Collins Jr LC, Spooner C, Hemann BA et al. (2015) A prospective study of the incidence of myocarditis/pericarditis and new onset cardiac symptoms following smallpox and influenza vaccination. PLoS One 10: e0118283. [Crossref]

52. Zawadowski GM, Klarich KW, Moder KG, Edwards WD, Cooper Jr LT (2012) A contemporary case series of lupus myocarditis. Lupus 21: 1378-1384. [Crossref]

53. Maisch B, Bültman B, Factor S, Grone HJ, Hufnagel G et al. (1994) World Heart Federation consensus conference's definition of inflammatory cardiomyopathy (myocarditis): report from two expert committees on histology and viral cardiomyopathy. Heartbeat 4: 3-4. [Crossref]

54. Maisch B, Richter A, Sandmöller A, Portig I, Pankuweit S (2005). Inflammatory dilated cardiomyopathy (DCMI). Herz 30: 535-544. [Crossref]

55. Kindermann I, Kindermann M, Kandolf R, Klingel K, Bültmann B et al. (2008) Predictors of outcome in patients with suspected myocarditis. Circ 118: 639-648. [Crossref]

56. Baughman KL (2006). Diagnosis of myocarditis: death of Dallas criteria. Circ 113 593-595. [Crossref]

57. Wojnicz R, Nowalany-Kozielska E, Wojciechowska C, Glanowska G, Wilczewski P et al. (2001) Randomized, placebo-controlled study for immunosuppressive treatment of inflammatory dilated cardiomyopathy: two-year follow-up results. Circ 104: 39-45. [Crossref]

58. Andréoletti L, Hober D, Becquart P, Belaich S, Copin MC et al. (1997) Experimental CVB3-induced chronic myocarditis in two murine strains: Evidence of interrelationships between virus replication and myocardial damage in persistent cardiac infection $\mathrm{J} \mathrm{Med}$ Virol 52: 206-214. [Crossref]

59. Liu PP, Mason JW (2001) Advances in the understanding of myocarditis. Circ 104: 1076-1082. [Crossref].

60. Matsumori A, Kawai C (1982) An animal model of congestive (dilated) cardiomyopathy: dilatation and hypertrophy of the heart in the chronic stage in DBA/2 mice with myocarditis caused by encephalomyocarditis virus. Circ 66: 355-360. [Crossref]

61. Huber SA, Gauntt CJ, Sakkinen P (1998) Enteroviruses and myocarditis: viral pathogenesis through replication, cytokine induction, and immunopathogenicity. $A d v$ Virus Res 1: 35-80b [Crossref]

62. Klingel K, Hohenadl C, Canu A, Albrecht M, Seemann M et al. (1992) Ongoing enterovirus-induced myocarditis is associated with persistent heart muscle infection: quantitative analysis of virus replication, tissue damage, and inflammationProc Natl Acad Sci 89: 314-318. [Crossref]

63. Martinez NE, Sato F, Kawai E, Omura S, Chervenak RP et al. (2012) Regulatory T cells and Th17 cells in viral infections: implications for multiple sclerosis and myocarditis. Future virology 7: 593-608. [Crossref]

64. Malkiel S, Kuan AP, Diamond B (1996) Autoimmunity in heart disease: mechanisms and genetic susceptibility. Mol Med Today 2: 336-342. [Crossref]

65. Dec Jr GW, Palacios IF, Fallon JT, Aretz HT, Mills J et al. (1985) Active myocarditis in the spectrum of acute dilated cardiomyopathies: clinical features, histologic correlates, and clinical outcome. N Engl J Med 312: 885-890. [Crossref]

66. Andreoletti L, Bourlet T, Moukassa D, Rey L, Hot D et al. (2000) Enteroviruses can persist with or without active viral replication in cardiac tissue of patients with endstage ischemic or dilated cardiomyopathy. J Infect Dis 182: 1222-1227. [Crossref]

67. Cooper Jr LT (2009) Myocarditis. N Engl J Med 360: 1526-1538. [Crossref]

68. Smith SC, Ladenson JH, Mason JW, Jaffe AS (1997) Elevations of cardiac troponin I associated with myocarditis: experimental and clinical correlates. Circ 95: 163-168. [Crossref]

69. Lauer B, Niederau C, Kühl U, Schannwell M, Pauschinger M et al. (1997). Cardiac troponin $\mathrm{T}$ in patients with clinically suspected myocarditis. $J$ Am Coll Cardiol 30: 1354-1359. [Crossref]
70. Mahfoud F, Gartner B, Kindermann M, Ukena C, Gadomski K et al. (2011) Virus serology in patients with suspected myocarditis: utility or futility?. Eur Heart $J 32$ : 897-903. [Crossref]

71. Bultmann BD, Klingel K, Näbauer M, Wallwiener D, Kandolf R (2005) High prevalence of viral genomes and inflammation in peripartum cardiomyopathy. $\mathrm{Am} \mathrm{J}$ Obstet Gynecol 193: 363-365. [Crossref]

72. Ukena C, Mahfoud F, Kindermann I, Kandolf R, Kindermann M et al. (2011) Prognostic electrocardiographic parameters in patients with suspected myocarditis. Eur Heart $J$ 13: 398-405. [Crossref]

73. Felker GM, Boehmer JP, Hruban RH, Hutchins GM, Kasper EK et al. (2000) Echocardiographic findings in fulminant and acute myocarditis. J Am Coll Cardiol 36 : 227-232. [Crossref]

74. Friedrich MG, Sechtem U, Schulz-Menger J, Holmvang G, Alakija P et al. (2009) Cardiovascular magnetic resonance in myocarditis: A JACC White Paper. $J$ Am Coll Cardiol 53: 1475-1487. [Crossref]

75. Aretz HT (1987) Myocarditis: the Dallas criteria. Human pathology 18: 619-624 [Crossref]

76. Cooper LT, Baughman KL, Feldman AM, Frustaci A, Jessup M et al. (2007) The role of endomyocardial biopsy in the management of cardiovascular disease: a scientific statement from the American Heart Association, the American College of Cardiology, and the European Society of Cardiology Endorsed by the Heart Failure Society of America and the Heart Failure Association of the European Society of Cardiology. $J$ Am Coll Cardiol 50: 1914-1931. [Crossref]

77. Leone O, Veinot JP, Angelini A, Baandrup UT, Basso C et al. (2012) 2011 consensus statement on endomyocardial biopsy from the Association for European Cardiovascular Pathology and the Society for Cardiovascular Pathology. Cardiovasc Pathol 21: 245274. [Crossref]

78. Sinagra G, Anzini M, Pereira NL, Bussani R, Finocchiaro G et al. (2016) Myocarditis in clinical practice. Mayo Clinic Proceedings 91: 1256-1266. [Crossref]

79. Dec GW (2016) How Should We Diagnose Myocarditis, and Is its Recognition Really Clinically Relevant? J Am Coll Cardiol 67: 1812-1814 [Crossref]

80. Moher D, Liberati A, Tetzlaff J, Altman DG (2009) Preferred reporting items for systematic reviews and meta-analyses: the PRISMA statement. Ann Intern Med 151: 264-269. [Crossref]

81. Gutberlet M, Spors B, Thoma T, Bertram H, Denecke T et al. (2008) Suspected chronic myocarditis at cardiac MR: diagnostic accuracy and association with immunohistologically detected inflammation and viral persistence. Radiology 246 401-409. [Crossref]

82. Lurz P, Eitel I, Klieme B, Luecke C, de Waha S et al. (2013) The potential additiona diagnostic value of assessing for pericardial effusion on cardiac magnetic resonance imaging in patients with suspected myocarditis. Eur Heart $J$ Cardiovasc Imaging 15: 643-650. [Crossref]

83. Sramko M, Kubanek M, Tintera J, Kautznerová D, Weichet J et al. (2013) Utility of combination of cardiac magnetic resonance imaging and high-sensitivity cardiac troponin T assay in diagnosis of inflammatory cardiomyopathy. Am J Cardiol 111: 258 264. [Crossref]

84. Francone M, Chimenti C, Galea N, Scopelliti F, Verardo R et al. (2014) CMR sensitivity varies with clinical presentation and extent of cell necrosis in biopsy-proven acute myocarditis. JACC: Cardiovas Imaging 7: 254-263. [Crossref]

85. Bohnen S, Radunski UK, Lund GK, Kandolf R, Stehning C et al. (2015) Performance of $\mathrm{t} 1$ and $\mathrm{t} 2$ mapping cardiovascular magnetic resonance to detect active myocarditis in patients with recent-onset heart failure. Circ Cardiovasc Imaging 8: e003073. [Crossref]

86. Lurz P, Luecke C, Eitel I, Föhrenbach F, Frank C et al. (2016) Comprehensive cardiac magnetic resonance imaging in patients with suspected myocarditis: the MyoRacerTrial. J Am Coll Cardiol 67: 1800-1811. [Crossref]

87. Krejci J, Mlejnek D, Sochorova D, Nemec P (2016) Inflammatory cardiomyopathy: a current view on the pathophysiology, diagnosis, and treatment. BioMed research international 2016. [Crossref]

88. Hulten E, Agarwal V, Cahill M, Cole G, Vita T, Parrish S et al. (2016) Presence of late gadolinium enhancement by cardiac magnetic resonance among patients with suspected cardiac sarcoidosis is associated with adverse cardiovascular prognosis: systematic review and meta-analysis. Circ Cardiovasc Imaging 9: e005001. [Crossref]

89. Kuruvilla S, Adenaw N, Katwal AB, Lipinski MJ, Kramer CM et al. (2014) Late gadolinium enhancement on cardiac magnetic resonance predicts adverse cardiovascular outcomes in nonischemic cardiomyopathy: a systematic review and meta-analysis. Circ Cardiovasc Imaging 7: 250-258. [Crossref] 
Albakri A (2018) Myocarditis heart failure: A review of clinical status and meta-analyses of diagnostic performance of cardiac magnetic resonance and therapeutic value of immunosuppressive therapy

90. Shehab AM, Strohm O (2010) Advanced tissue characterization in non-ischemic cardiomyopathies using contrast-enhanced cardiac magnetic resonance imaging. Saudi Med J, 2010; 31: 115-122. [Crossref]

91. Eitel I, Friedrich MG (2011) T2-weighted cardiovascular magnetic resonance in acute cardiac disease. J Cardiovasc Magn Reson 13: 13. [Crossref]

92. Eitel I, Lücke C, Grothoff M, Sareban M, Schuler G et al. (2010) Thiele H, Gutberlet M. Inflammation in takotsubo cardiomyopathy: insights from cardiovascular magnetic resonance imaging. Eur Radiol 20: 422-431. [Crossref]

93. Greaves K, Oxford JS, Price CP, Clarke GH, Crake T (2003) The prevalence of myocarditis and skeletal muscle injury during acute viral infection in adults: measurement of cardiac troponins I and $\mathrm{T}$ in 152 patients with acute influenza infection. Arch Intern Med 163: 165-168. [Crossref]

94. Ponikowski P, Voors AA, Anker SD, Bueno H, Cleland JG, et al. (2016) 2016 ESC Guidelines for the diagnosis and treatment of acute and chronic heart failure: The Task Force for the diagnosis and treatment of acute and chronic heart failure of the European Society of Cardiology (ESC) Developed with the special contribution of the Heart Failure Association (HFA) of the ESC. Eur Heart J 37: 2129-2200. [Crossref]

95. Japanese Circulation Society (JCS) Joint Working Group (2011) Guidelines for diagnosis and treatment of myocarditis (JCS 2009). Circ J 75: 734-743. [Crossref]

96. Mirabel M, Luyt CE, Leprince P, Trouillet JL, Léger P et al. (2011) Outcomes, longterm quality of life, and psychologic assessment of fulminant myocarditis patients rescued by mechanical circulatory support. Crit Care Med 39: 1029-1035. [Crossref]

97. Chen YS, Wang MJ, Chou NK, Han YY, Chiu S et al. (1999) Rescue for acute myocarditis with shock by extracorporeal membrane oxygenation. Ann Thorac Surg 68: 2220-2224. [Crossref]

98. Hsu KH, Chi NH, Yu HY, Wang CH, Huang SC et al. (2011) Extracorporeal membranous oxygenation support for acute fulminant myocarditis: analysis of a single center's experience. Eur J Cardiothorac Surg 40: 682-688. [Crossref]

99. McMurray JJ, Adamopoulos S, Anker SD, Auricchio A, Bohm M, et al. (2012) ESC Guidelines for the diagnosis and treatment of acute and chronic heart failure 2012: The Task Force for the Diagnosis and Treatment of Acute and Chronic Heart Failure 2012 of the European Society of Cardiology. Developed in collaboration with the Heart Failure Association (HFA) of the ESC. Eur J Heart Fail 14: 803-869. [Crossref]

100. Woodruff JF (1980) Viral myocarditis. A review. Am J Pathol 101: 425-484 [Crossref]

101. Prochnau D, Surber R, Kuehnert H, Heinke M, Klein HU et al. (2010) Successful use of a wearable cardioverter-defibrillator in myocarditis with normal ejection fraction. Clin Res Cardiol 99: 129-131. [Crossref]

102. Basso C, Carturan E, Corrado D, Thiene G et al. (2007) Myocarditis and dilated cardiomyopathy in athletes: diagnosis, management, and recommendations for sport activity. Cardiol Clin 25: 423-429. [Crossref]

103. Pelliccia A, Fagard R, Bjornstad HH, Anastassakis A, Arbustini E et al. (2005) Assanelli D, Biffi A, Borjesson M, Carre F, Corrado D, Delise P. Recommendations for competitive sports participation in athletes with cardiovascular disease. Eur Heart J 26: 1422-1445. [Crossref]
104. Krueger GR, Ablashi DV (2003) Human herpesvirus-6: a short review of its biological behavior. Intervirology 46: 257-269. [Crossref]

105. Kuhl U, Pauschinger M, Schwimmbeck PL, Seeberg B, Lober C et al. (2003) Interferon- $\beta$ treatment eliminates cardiotropic viruses and improves left ventricular function in patients with myocardial persistence of viral genomes and left ventricular dysfunction. Circ 107: 2793-2798. [Crossref]

106. McNamara DM, Holubkov R, Starling RC, Dec GW, Loh E et al. (2001) Controlled trial of intravenous immune globulin in recent-onset dilated cardiomyopathy. Circ 103: 2254-2259. [Crossref]

107. Felix SB, Staudt A, Landsberger M, Grosse Y, Stangl V et al. (2002) Removal of cardiodepressant antibodies in dilated cardiomyopathy by immunoadsorption. $\mathrm{J} \mathrm{Am}$ Coll Cardiol 39: 646-652. [Crossref]

108. Doesch AO, Konstandin M, Celik S, Kristen A, Frankenstein L et al. (2009) Effects of protein A immunoadsorption in patients with advanced chronic dilated cardiomyopathy. J Clin Apher 24: 141-149. [Crossref]

109. Herda LR, Trimpert C, Nauke U, Landsberger M, Hummel A et al. (2010) Effects of immunoadsorption and subsequent immunoglobulin $\mathrm{G}$ substitution on cardiopulmonary exercise capacity in patients with dilated cardiomyopathy. $\mathrm{Am}$ Heart J 159: 809-816. [Crossref]

110. Felix SB, Staudt A, Dörffel WV, Stangl V, Merkel K et al. (2000) Hemodynamic effects of immunoadsorption and subsequent immunoglobulin substitution in dilated cardiomyopathy: three-month results from a randomized study. J Am Coll Cardiol 35: 1590-1598. [Crossref]

111. Parrillo JE, Cunnion RE, Epstein SE, Parker MM, Suffredini AF et al. (1989) A prospective, randomized, controlled trial of prednisone for dilated cardiomyopathy. New England Journal of Medicine. 1989 Oct 19;321(16):1061-1068. [Crossref]

112. Latham RD, Mulrow JP, Virmani R, Robinowitz M, Moody JM (1989) Recently diagnosed idiopathic dilated cardiomyopathy: incidence of myocarditis and efficacy of prednisone therapy. Am Heart J 117: 876-882. [Crossref]

113. Miric M, Vasiljevic J, Bojic M, Popovic Z, Keserovic N et al. (1996) Long-term follow up of patients with dilated heart muscle disease treated with human leucocytic interferon alpha or thymic hormones initial results. Heart 75: 596-601. [Crossref]

114. Frustaci A, Russo MA, Chimenti C (2009) Randomized study on the efficacy of immunosuppressive therapy in patients with virus-negative inflammatory cardiomyopathy: the TIMIC study. Eur Heart J 30: 1995-2002. [Crossref]

115. Kishimoto C, Shioji K, Hashimoto T, Nonogi H, Lee JD et al. [2014] Therapy with immunoglobulin in patients with acute myocarditis and cardiomyopathy: analysis of leukocyte balance. Heart and vessels 29: 336-342. [Crossref]

116. Winter MP, Sulzgruber P, Koller L, Bartko P, Goliasch G et al. (2008) Immunomodulatory treatment for lymphocytic myocarditis: a systematic review and meta-analysis. Heart Fail Rev 23:573-581. [Crossref]

117. Liu C, Chen J, Liu K (2005). Immunosuppressive treatment for inflammatory cardiomyopathy. Int Heart J 46: 113-122. [Crossref]

Copyright: $\odot 2018$ Albakri A. This is an open-access article distributed under the terms of the Creative Commons Attribution License, which permits unrestricted use, distribution, and reproduction in any medium, provided the original author and source are credited. 